\title{
ChemComm
}

Cite this: Chem. Commun., 2013, 49,4824

Received 4th February 2013, Accepted 5th April 2013

DOI: $10.1039 / c 3 c c 40937 f$

www.rsc.org/chemcomm

\section{Bis[zinc(II)dipicolylamino]-functionalised peptides as high affinity receptors for pyrophosphate ions in water ${ }^{+}$}

\author{
Karen K. Y. Yuen and Katrina A. Jolliffe*
}

\begin{abstract}
A library of bis[zinc(II)dipicolylamine]-functionalised linear peptides was prepared using an efficient solid phase peptide synthesis approach and their use as chemosensors for anions in water was investigated using indicator displacement assays. High affinity and selectivity for pyrophosphate (PPi) over adenosine triphosphate (ATP) and adenosine diphosphate (ADP) were observed and additional aromatic side chains provided enhanced discrimination between PPi and ATP.
\end{abstract}

Anions play fundamental roles in numerous important biological and chemical processes. In particular, phosphate oxoanions such as pyrophosphate (PPi) and adenosine triphosphate (ATP) are involved in a number of bioenergetic and metabolic processes. Therefore there is intense current interest in developing receptors that can efficiently and selectively detect phosphate oxoanions under physiological conditions. ${ }^{1,2}$

Bis[Zn(II)dipicolylamine] [Zn(II)Dpa] receptors have been found to exhibit good selectivity for phosphates over other anions in aqueous solution. ${ }^{2}$ In recent studies we have observed that cyclic peptide derived bis[Zn(II)Dpa] receptors can be tuned to show selectivity for PPi over ATP using indicator displacement assays through altering of the cyclic peptide structure. ${ }^{3,4}$ Notably, both the structure of 'non-binding' amino acid side chains decorating the scaffolds and the size of the cyclic peptide have a significant impact on receptor selectivity and affinity. ${ }^{4}$ In order to further probe the interesting effect of 'non-binding' side chains on receptor selectivity we desired rapid access to libraries of peptide scaffolds with varying structures. However, the synthesis and purification of such cyclic peptides is experimentally complex and time-consuming. We envisaged that receptors with simpler linear peptides scaffolds, which should be readily accessible by solid phase synthesis, would provide efficient access to a library of receptors for screening the effects of different side chains on receptor selectivity.

School of Chemistry, The University of Sydney, 2006, NSW, Australia.

E-mail: kate.jolliffe@sydney.edu.au; Fax: +61 29351 3329; Tel: +61 293512297

$\dagger$ Electronic supplementary information (ESI) available: Synthetic procedures and NMR spectra for all new compounds and anion titration data. See DOI: 10.1039/ c3cc40937f
To enable rapid access to a library of receptors, we developed a synthetic route that would enable the entire synthesis, prior to addition of the zinc(II) ions, to be performed on the solid phase.

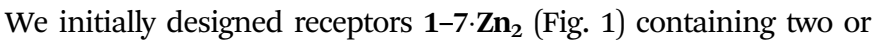
three amino acids and attempted their synthesis using Fmoc solid phase peptide synthesis (Fmoc-SPPS) (Scheme 1). Orthogonal allyloxycarbonyl (Alloc) protecting groups were employed for protection of the side chain amino groups. Following synthesis of the desired linear peptide sequences using standard Fmoc-SPPS protocols on Rink amide resin and acetyl capping of the $N$-terminal
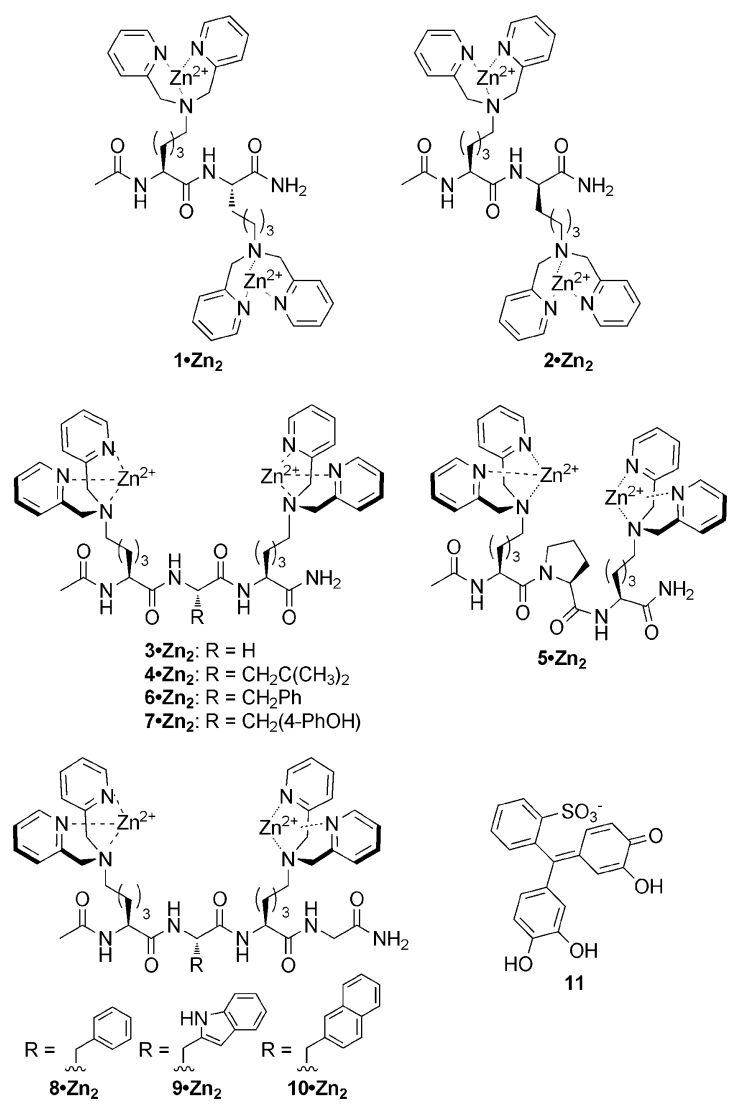

Fig. 1 Structures of receptors $1-10 \cdot Z n_{2}$ and indicator 11 . 


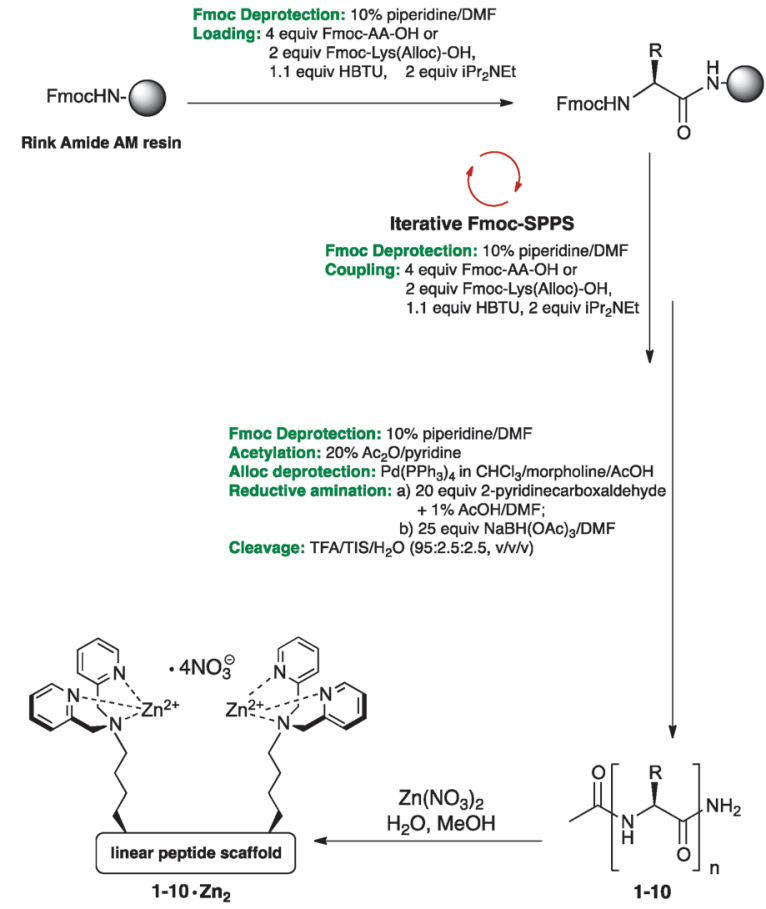

Scheme 1 General method for synthesis of linear peptides on Rink Amide AM resin via Fmoc-SPPS strategy.

amino acid, the Alloc groups were removed upon treatment with $\mathrm{Pd}\left(\mathrm{PPh}_{3}\right)_{4}$ (1.05 equiv.) in the presence of acetic acid and morpholine. ${ }^{5}$ Subsequent reductive aminations with picolylaldehyde $^{6}$ to install the dipicolylamino groups were only partially successful and in some cases the reaction could not be forced to completion despite subjecting the solid phase bound peptides to repetitive reaction attempts. After analysis of the partially alkylated products following cleavage from the resin, we established that reductive amination of the amino acid directly attached to the resin was not proceeding to completion, presumably as a result of difficulties of reagent access to this hindered amino group. Therefore, for the synthesis of receptors $\mathbf{8 - 1 0} \cdot \mathbf{Z n}_{\mathbf{2}}$, a $C$-terminal glycine residue was incorporated as a spacer between the resin and the residue to be reacted. In these cases, the reductive aminations readily proceeded to completion after two reaction cycles, confirming that steric hindrance by the resin was the cause of the previous incomplete conversions. Subsequent cleavage of the peptides from the resin was followed by HPLC purification and addition of two equivalents of $\mathrm{Zn}\left(\mathrm{NO}_{3}\right)_{2}$ provided receptors $\mathbf{1 - 1 0} \cdot \mathbf{Z n}_{2}$.

The anion binding capabilities of receptors $\mathbf{1 - 1 0} \cdot \mathbf{Z n}_{\mathbf{2}}$ were investigated using indicator displacement assays (IDAs) with the colourimetric indicator pyrocatechol violet (11), which has previously been employed in IDAs with bis[Zn(II)Dpa] complexes. ${ }^{7}$ This indicator provides the ability to rapidly screen anion binding to receptor libraries through naked eye visualisation, which can then be followed by measurement of binding affinities by UV-Vis spectroscopy for positive hits. IDAs were performed with $1: 1$ receptor-indicator chemosensing ensembles prepared by mixing equimolar amounts $(20 \mu \mathrm{M})$ of receptors $\mathbf{1}-\mathbf{1 0} \cdot \mathbf{Z n}_{2}$ and indicator 11 in buffered saline solution ( $\mathrm{pH}$ 7.4, 5 mM HEPES, $145 \mathrm{mM}$ $\mathrm{NaCl})$. Upon addition of five equivalents of a range of anions as their sodium salts (PPi, ATP, ADP, AMP, cAMP, pThr, pSer, citrate,

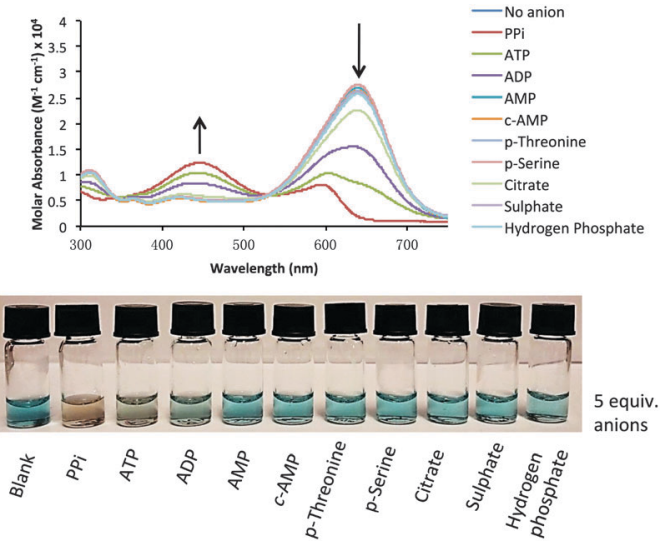

Fig. 2 Qualitative screening of $\mathbf{9 \cdot} \mathbf{Z} \mathrm{n}_{\mathbf{2}} \cdot \mathbf{1 1}$ after addition of 5 equiv. of anions to a $20 \mu \mathrm{M}$ receptor: indicator solution. UV-vis spectra (top) and visual screening (bottom).

$\mathrm{SO}_{4}{ }^{2-}$ and $\mathrm{HPO}_{4}{ }^{2-}$ ), it was found that in most cases only PPi, ATP and ADP resulted in a colour change indicative of indicator displacement (Fig. 2). UV-Vis spectroscopic analysis of the resulting solutions indicated that in some cases a small change in absorbance was also observed upon addition of citrate, although the change was not large enough to be visible to the naked eye.

Association constants for the indicator-receptor complexes were determined by UV-Vis spectroscopic titration experiments and non-linear least squares fitting of the titration data to a $1: 1$ binding model using Hypspec ${ }^{\mathbb{R}}{ }^{8}$ (Table 1 and Fig. 3). The $1: 1$ binding stoichiometry was confirmed by Job plot analysis (Fig. 3, bottom). Subsequently, the 1:1 indicator : receptor mixtures were titrated with aliquots of the sodium salts of PPi, ATP and ADP (Fig. 4). Curve fitting of the absorbance data $(250-750 \mathrm{~nm})$ based on the previously described equilibria for competition assays ${ }^{9}$ using Hypspec $^{\circledR}$ provided apparent association constants for the receptor:anion complexes. In all cases the receptors exhibited very strong binding to PPi $\left(\log K_{\mathrm{a}}\right.$ ranging from 7.8 to 9$)$ in these mimicked physiological conditions and some selectivity for PPi over ATP and ADP was also observed. Of this library of receptors, dipeptide receptor $\mathbf{1} \cdot \mathbf{Z} \mathbf{n}_{2}$ was the least effective at discriminating between polyphosphate species. In contrast, dipeptide receptor $\mathbf{2} \cdot \mathbf{Z n}_{2}$, which contains alternating $\mathrm{L}_{\mathrm{L}}$ and $\mathrm{D}$-amino acids exhibited

Table 1 Apparent association constants $\left(\log K_{\mathrm{a}}\right.$ ) determined for receptors $1-10 \cdot Z n_{2}$ and various polyphosphate anions

\begin{tabular}{lllcll}
\hline & \multirow{2}{*}{$\begin{array}{l}\text { 'Spacer' } \\
\text { Receptor }\end{array}$} & \multicolumn{4}{l}{ Apparent association constants $\left(\log K_{\mathrm{a}}\right)$} \\
\cline { 3 - 6 } & amino acid & Indicator 11 & PPi & ATP & ADP \\
\hline $\mathbf{1} \cdot \mathbf{Z n}$ & - & 6.6 & 8.7 & 7.2 & 5.8 \\
$\mathbf{2} \cdot \mathbf{Z n}_{2}$ & - & 6.6 & $>9$ & 6.6 & 5.3 \\
$\mathbf{3} \cdot \mathbf{Z n}$ & Gly & 5.4 & 7.8 & 5.4 & 4.2 \\
$\mathbf{4} \cdot \mathbf{Z n}_{2}$ & Leu & 7.4 & $>9$ & 7.1 & 5.3 \\
$\mathbf{5} \cdot \mathbf{Z n}_{2}$ & Pro & 6.8 & $>9$ & 6.5 & 4.9 \\
$\mathbf{6} \cdot \mathbf{Z n}_{2}$ & Phe & 8.3 & $>9$ & 8.2 & 5.5 \\
$\mathbf{7} \cdot \mathbf{Z n}_{2}$ & Tyr & 6.9 & $>9$ & 6.7 & 5.0 \\
$\mathbf{8} \cdot \mathbf{Z n}_{2}$ & Phe & 8.2 & $>9$ & 7.8 & 5.3 \\
$\mathbf{9} \cdot \mathbf{Z n}_{2}$ & Trp & 7.0 & $>9$ & 6.4 & 4.6 \\
$\mathbf{1 0} \cdot \mathbf{Z n}_{2}$ & Nal & 6.1 & $>9$ & 5.9 & 4.7
\end{tabular}

${ }^{a}$ Titrations performed at $25^{\circ} \mathrm{C}$ in aqueous solutions buffered at $\mathrm{pH} 7.4$ with $5 \mathrm{mM}$ HEPES in the presence of $145 \mathrm{mM} \mathrm{NaCl}$. Estimated error in $\log K_{\mathrm{a}}>0.2$. 

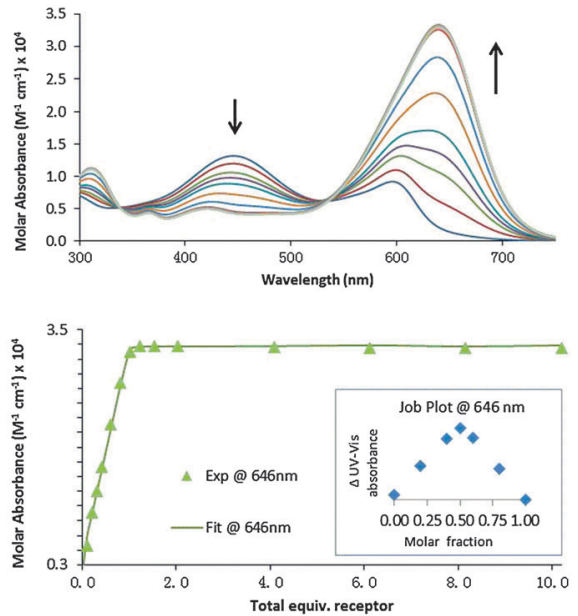

Fig. 3 Representative spectra showing the change in molar absorbance of indicator $\mathbf{1 1}(20 \mu \mathrm{M})$ upon addition of increasing amounts of $\mathbf{9} \cdot \mathbf{Z n _ { 2 }}$ (top); fitting curve for $1: 1$ binding between $\mathbf{9 \cdot} \cdot \mathrm{Zn}_{2}$ and indicator 11 at $646 \mathrm{~nm}$ (bottom; Job Plot inset). Measurement conditions: aqueous solution of HEPES buffer $(5 \mathrm{mM}$, $\mathrm{pH} 7.4,145 \mathrm{mM} \mathrm{NaCl}), \lambda_{\text {abs }} 250-750 \mathrm{~nm}, 25^{\circ} \mathrm{C}$.

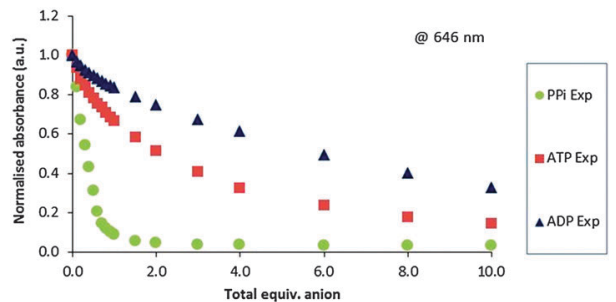

Fig. 4 Representative spectra showing absorbance changes at $646 \mathrm{~nm}$ of $\mathbf{9} \cdot \mathbf{Z n _ { 2 }}$ 11 ensemble upon addition of various anions (up to 10 equiv.). Measurement conditions: aqueous solution of HEPES buffer ( $5 \mathrm{mM}, \mathrm{pH} 7.4,145 \mathrm{mM} \mathrm{NaCl}), \lambda_{\text {abs }}$ $250-750 \mathrm{~nm}, 25^{\circ} \mathrm{C}$.

high affinity and excellent selectivity for PPi over ATP and ADP, indicating the importance of receptor stereochemistry and suggesting that, despite the inherent flexibility in the Lys derived Zn(II)Dpa side chains, positioning these on the same face of the scaffold increases selectivity.

We reasoned that the inclusion of a spacer amino acid between two L-configured Zn(II)Dpa residues should provide similar geometrical positioning of the sidechains, ${ }^{10}$ with an increased space between them which might also provide an increase in binding affinity. As anticipated, most of the tripeptide and tetrapeptide-based receptors $\left(\mathbf{3}-\mathbf{1 0} \cdot \mathbf{Z n}_{\mathbf{2}}\right)$ displayed enhanced affinity and selectivity for PPi over ATP and ADP when compared to $\mathbf{1} \cdot \mathbf{Z n}_{\mathbf{2}}$ and similar affinities and selectivity to $\mathbf{2} \cdot \mathbf{Z n}_{2}$. The introduction of side chain functionalities on the spacer amino acid was found to have significant effects on both binding affinity and selectivity. Notably, the incorporation of a hydrophobic residue in the peptide sequence $\left(\mathbf{4}-\mathbf{1 0} \cdot \mathbf{Z n}_{2}\right)$ resulted in a substantial increase in affinity for both PPi and ATP, when compared to the affinities obtained for the Gly derivative $\mathbf{3} \cdot \mathbf{Z n}_{2}$. A comparison of the binding data for $\mathbf{6} \cdot \mathbf{Z n}_{2}$ and $\mathbf{8} \cdot \mathbf{Z n}_{2}$ indicates that the addition of a Gly residue at the $C$-terminus (to facilitate solid phase synthesis) has little effect on binding affinity or selectivity. While $\mathbf{4 - 1 0} \cdot \mathbf{Z n}_{2}$ all bound PPi with affinity too high to quantify $\left(\log K_{\mathrm{a}}>9\right)$ under the current competitive conditions, analysis of the difference in their affinity for ATP provides some indication of receptor ability to discriminate between ATP and PPi. Incorporation of a Pro residue to provide a more defined peptide backbone conformation did not have a significant impact on binding affinity or selectivity, with similar binding behaviour observed for the Leu $\left(\mathbf{4} \cdot \mathbf{Z n}_{2}\right)$ and Pro $\left(\mathbf{5} \cdot \mathbf{Z n}_{2}\right)$ derivatives. Notably compounds $\mathbf{9} \cdot \mathbf{Z n}_{\mathbf{2}}$ and $\mathbf{1 0} \cdot \mathbf{Z n}_{2}$, which bear large aromatic spacer residues (Trp and Nal, respectively) had reduced affinity for ATP. While the reason for this requires further investigation, these results indicate that the incorporation of hydrophobic and aromatic residues can be used to tune the anion recognition abilities of such scaffolds to provide better discrimination between anions of similar charge.

In conclusion, the design, synthesis, and anion binding capabilities of a library of linear peptide-based receptors (1-10. $\left.\mathbf{Z n}_{2}\right)$, bearing two $\mathrm{Zn}(\mathrm{II}) \mathrm{Dpa}$ binding sites are reported. Receptors $\mathbf{2}, \mathbf{9}$ and $\mathbf{1 0} \cdot \mathbf{Z n}_{2}$ show remarkably strong binding to PPi with significant selectivity over ATP and ADP under mimicked physiological conditions. Studies to elucidate the reasons for the enhanced binding selectivities exhibited by receptors with hydrophobic and aromatic side chains are currently in progress.

The Australian Research Council is acknowledged for financial support. KKYY thanks the University of Sydney for the award of a Gritton Postgraduate Scholarship. We thank Dr H. T. Ngo (USyd) for assistance with data analysis using Hyperquad ${ }^{\mathbb{R}}$.

\section{Notes and references}

1 A. E. Hargrove, S. Nieto, T. Zhang, J. L. Sessler and E. V. Anslyn, Chem. Rev., 2011, 111, 6603; P. A. Gale, Chem. Commun., 2011, 47, 82; S. Kubik, Chem. Soc. Rev., 2010, 39, 3648; S. K. Kim, D. H. Lee, J.-I. Hong and J. Yoon, Acc. Chem. Res., 2008, 42, 23; J. L. Sessler, P. A. Gale and W.-S. Cho, Anion Receptor Chemistry, Royal Society of Chemistry, Cambridge, 2006.

2 H. T. Ngo, X. Liu and K. A. Jolliffe, Chem. Soc. Rev., 2012, 41, 4928.

3 S. J. Butler and K. A. Jolliffe, Org. Biomol. Chem., 2011, 9, 3471; J. V. Carolan, S. J. Butler and K. A. Jolliffe, J. Org. Chem., 2009, 74, 2992; M. J. McDonough, A. J. Reynolds, G. W. Y. Lee and K. A. Jolliffe, Chem. Commun., 2006, 2971.

4 X. Liu, H. T. Ngo, Z. Ge, S. J. Butler and K. A. Jolliffe, Chem. Sci., 2013, 4, 1680; S. J. Butler and K. A. Jolliffe, Chem.-Asian. J., 2012, 7, 2621.

5 S. A. Kates, S. B. Daniels and F. Albericio, Anal. Biochem., 1993, 212, 303.

6 Y. Azuma, H. Imai, T. Yoshimura, T. Kawabata, M. Imanishi and S. Futaki, Org. Biomol. Chem., 2012, 10, 6062; L. Quinti, R. Weissleder and C.-H. Tung, Nano Lett., 2006, 6, 488.

7 M. S. Han and D. H. Kim, Angew. Chem., Int. Ed., 2002, 41, 3809; M. S. Han and D. H. Kim, Bull. Korean Chem. Soc., 2004, 25, 1151; R. G. Hanshaw, E. J. O'Neil, M. Foley, R. T. Carpenter and B. D. Smith, J. Mater. Chem., 2005, 15, 2707; M. K. Coggins, A. M. Parker, A. Mangalum, G. A. Galdamez and R. C. Smith, Eur. J. Org. Chem., 2009, 343.

8 P. Gans, A. Sabatini and A. Vacca, Talanta, 1996, 43, 1739.

9 K. A. Connors, Binding Constants: The Measurements of Molecular Complex Stability, John Wiley and Sons, 1987.

10 K. M. DiVittorio, J. R. Johnson, E. Johansson, A. J. Reynolds, K. A. Jolliffe and B. D. Smith, Org. Biomol. Chem., 2006, 4, 1966. 